\title{
Self-healing coatings for inhibiting corrosion of ferrous metals exposed to preservative-treated bamboo
}

\author{
Qingping Wang ${ }^{1,2}$, Jinzhen $\mathrm{CaO}^{2}$, Xing'e Liu ${ }^{3}$, Shumin Yang ${ }^{3}$ and Mingliang Jiang ${ }^{1 *}$
}

\begin{abstract}
This study aims to provide an effective method of inhibiting the corrosion of ferrous metals exposed to preservativetreated bamboo, thereby prolonging material service life and reducing maintenance costs. The synthesis and characterization of microcapsules were first described. The characterization included the particle size, surface morphology, thermal stability, and core content of microcapsules. The results showed that microcapsules had good thermal stability and high core loading. Then, the self-healing performance and corrosion resistance of self-healing coatings were evaluated. The results indicated that self-healing coatings can identify and heal the damage automatically and had a more positive effect on inhibiting metal corrosion. Also, the mechanical properties of self-healing coatings were analyzed. The results demonstrated that microcapsule embedment did not almost affect the mechanical properties of self-healing coatings.
\end{abstract}

Keywords: Self-healing coating, Ferrous metal corrosion, Preservative-treated bamboo, Microcapsule, Organic preservative

\section{Introduction}

Bamboo is an important renewable biomass material with characteristics of high strength, high hardness, strong toughness, low weight, fast growth and low costs $[1,2]$. Currently, bamboo has been used in engineering, construction, packaging, furniture and decoration [3-5]. Nevertheless, bamboo is extremely susceptible to attack by decay fungi and mold fungi due to containing plentiful organic nutrients, such as starch, protein, sugar and fat [6]. Preservative treatment can prevent bamboo from biodegradation $[7,8]$, but it may bring a risk to facilitate ferrous metal corrosion in humid environment.

Over the past decades, studies have showed that preservative-treated wood can lead to the corrosion of ferrous metals $[9,10]$. Although there has been no report on the metal corrosion of treated bamboo to date, the metal

\footnotetext{
${ }^{*}$ Correspondence: jiangml@caf.ac.cn

1 Research Institute of Wood Industry, Chinese Academy of Forestry, Beijing 100091, People's Republic of China

Full list of author information is available at the end of the article
}

corrosion mechanism of treated bamboo can be partially inferred from the research results of treated wood since wood chemical compositions are similar to bamboo [11, 12]. The corrosion of ferrous metals exposed to treated wood is essentially an electrochemical corrosion cell [13, 14]. It involves the transfer of ions and electrons between a metal surface and an electrolytic solution. This transfer is believed to be an aqueous process. Baechler [15] evaluated the corrosion of metal fastenings in zinc chloride-treated wood and pointed out that the severity of corrosion increased with relative humidity. Dennis et al. [16] and Short and Dennis [17] studied the influence of moisture content on the corrosion rate of metals embedded in preservative-treated timber and found a sigmoidal dependence of corrosion rate on moisture content. At the same time, moisture can accelerate hydrolysis of the $O$-acetyl groups lying in the hemicellulose to form organic acids, consequently facilitating metal corrosion [18]. Therefore, controlling moisture content has an important influence on inhibiting the ferrous metal corrosion of treated bamboo. 
Coatings can act as a protective barrier that is available for preventing moisture from entering the interface between bamboo and metal, consequently controlling or delaying the onset of corrosion. Although coatings are a cost-effective and facile method for corrosion prevention, they undergo changes in surface morphology in high humidity leading to the formation and propagation of microcracks which subsequently result in the coating failure. This failure behavior will result in the economic losses in inspection, maintenance and repair. Hence, the introduction of a novel and creative technology is needed to improve the coating quality. Self-healing coatings can identify and heal the microcracks autonomically, thereby restoring effectively the functionality and structural integrity of coatings after the damage. The concept of self-healing has its roots in biology [19]. According to the healing ways, self-healing coatings can be divided broadly into three classes [20]: (i) intrinsic-the intrinsic system achieves self-healing functionality through inherent reversibility of bonding of the material itself; (ii) vascular and (iii) microcapsule-based-the vascular and microcapsule-based systems trigger self-healing mechanism through the release and reaction of the secondary phase healing agent in the region of damage. Recently, much attention has been paid to self-healing coatings embedded by microcapsules. Compared with the intrinsic and vascular systems, the microcapsule-based self-healing system has the advantages of fast response to crack, simple synthesis, low cost and ease of dispersion in the polymer matrix $[21,22]$.

A typical microcapsule-based system employs a microencapsulated healing agent and a (microencapsulated) catalyst. In the system, catalysts must be dispersed into the matrix or need to be encapsulated to maintain their activity in some cases, which would make the self-healing mechanism quite complex. And catalysts, as a second separated phase, can lead to an increased discontinuity in the coating matrix. At the same time, the cost, availability, stability and toxicity of catalysts can limit the application of self-healing coatings. Use of an oxidative healing agent can solve this problem. Tung oil is a drying oil obtained from the nut of the tung tree (Aleurites fordii), which is a natural triglyceride containing high percentage of polyunsaturated fatty acids with air-drying property. These polyunsaturated fatty acids are readily oxidized to form a three-dimensional network that isolates moisture. Some researchers [23-26] have showed the self-healing ability of encapsulated tung oil in poly(urea-formaldehyde) (PUF) shell without any catalysts.

In the past, copper-based preservatives [27, 28], such as chromated copper arsenate (CCA), alkaline copper quat $(\mathrm{ACQ})$ and copper azole $(\mathrm{CuAz})$, were widely used to protect bamboo. Although these preservatives are very efficient in preventing biodegradation, they are harmful or threatening to the local ecosystems and the health of human and animal [27]. In recent years, people are increasingly concerned about the effect of wood preservatives on their health. Some scholars consider that organic preservatives are more environmentally friendly and have more development potential [27-29]. And there is a general expectation that organic preservatives can replace copper-containing preservatives for outdoor applications [28]. Triazoles, iodopropynyl butylcarbamate (IPBC) and isothiazolinones are several commercialized organic preservatives with advantages of high efficiency, low toxicity, broad spectrum and colorless $[27,30]$. They were originally designed and introduced as agricultural biocides and cosmetic preservatives and are currently used as bamboo preservatives with good prospects for development.

Currently, there has been no research on self-healing coating for preservative-treated bamboo (and wood), although several studies on self-healing coating for steel or concrete have been reported [23, 25, 31-34]. It is well known that the material properties of steel or concrete and bamboo are obviously different [35]. The hygroscopic nature of bamboo results in the continuous volumetric change of treated bamboo leading to coating damage. This effect increases permeability, driving the occurrence of corrosion. Hence, it is necessary to investigate whether self-healing coatings are suitable for inhibiting the corrosion of ferrous metals exposed to preservative-treated bamboo.

In the present study, the effect of self-healing coatings on the corrosion of ferrous metals exposed to preservative-treated bamboo was investigated. The characterization included the morphology and thermal stability of microcapsules as well as the self-healing behavior, corrosion resistance and mechanical property of self-healing coatings. This study aims to provide an effective method of inhibiting the corrosion of ferrous metals exposed to preservative-treated bamboo, thereby prolonging material service life and reducing maintenance costs.

\section{Materials and methods Materials}

Moso bamboo (Phyllostachys edulis) of 4 years old and 5-7\% moisture content was collected from Hangzhou, Zhejiang Province, China. Tung oil was obtained from Enshi, Hubei Province, China. Carbon steel (Q235) and spring steel $(65 \mathrm{Mn})$ were purchased from the market $[36,37]$. Waterborne coatings are considered to be more environmentally friendly and have more development potential [38]. Therefore, waterborne polyurethane and waterborne acrylate, two of the most popular varnishes in the Chinese market, were selected in this study. 
Waterborne polyurethane varnish (CYWNC-200) and waterborne acrylate varnish (CYWNC-201) were supplied by Hebei Chenyang Industry and Trade Group Co., Ltd., Baoding, China.

Propiconazole (PPZ) (96.4 wt\%) and tebuconazole (TEB) (97 wt\%) were provided by Shanghai Shengnong Pesticide Co., Ltd., Shanghai, China. IPBC (AR, 99 wt\%) was provided from Shanghai Huilong Chemical Co., Ltd., Shanghai, China. Isothiazolinone (MCI-MI) (14 wt\%) was provided from Beijing Sunpu Biochemical Technology Co., Ltd., Beijing, China. Urea (AR) and ammonium chloride $\left(\mathrm{NH}_{4} \mathrm{Cl}\right)(\mathrm{AR})$ were procured from Xilong Scientific Co., Ltd., Shantou, China. Resorcinol (AR, 99 wt\%), poly(vinyl alcohol) (PVA) (alcoholysis degree: 92.0$94.0 \mathrm{~mol} \%$ and viscosity: $23.0-30.0 \mathrm{mPa}$ s), sodium dodecyl sulfate (SDS) ( $\geq 99.0 \mathrm{wt} \%$ ) and octanol (AR, $99.0 \mathrm{wt} \%$ ) were procured from Aladdin Industrial Corporation, Shanghai, China. Formaldehyde (37 wt\%) was purchased from Shandong Baiqian Chemical Co., Ltd., Jinan, China. All chemicals were used as received.

\section{Synthesis and characterization of microcapsules}

The microencapsulation of tung oil was adapted from the methodology described by Samadzadeh et al. [23]. The encapsulation process of microcapsules is as follows.

At room temperature, $260 \mathrm{ml}$ of deionized water and $10 \mathrm{ml}$ of aqueous solution of $4 \mathrm{wt} \%$ PVA and $1 \mathrm{wt} \%$ SDS were mixed in a beaker. Under mechanical agitation, $5 \mathrm{~g}$ urea, $0.5 \mathrm{~g} \mathrm{NH}_{4} \mathrm{Cl}$ and $0.5 \mathrm{~g}$ resorcinol were added into the resultant solution. One to two drops of octanol was added to eliminate surface bubbles. The $\mathrm{pH}$ was adjusted to $3.0-3.5$ with a $1 \mathrm{wt} \% \mathrm{HCl}$ aqueous solution. After $10 \mathrm{~min}$ of agitation, $50 \mathrm{ml}$ of tung oil was added slowly to form an emulsion and allowed to stabilize for 20-30 $\mathrm{min}$ under agitation. After stabilization, $13.0 \mathrm{~g}$ of $37 \mathrm{wt} \%$ formaldehyde solution was poured into the emulsion. The emulsion was covered and slowly heated and maintained at $60{ }^{\circ} \mathrm{C}$ under stirring at $400 \mathrm{rpm}$ for $4 \mathrm{~h}$. At the completion of the reaction, the mechanical agitation and heating were stopped and the reaction mixture was cooled to room temperature. Microcapsules were separated by filtration under vacuum with coarse filter paper. After separation, the solids were washed twice with deionized water and acetone, and then air-dried for $48 \mathrm{~h}$ prior to use.

The particle size of microcapsules was determined using an optical microscopy (Leica DMLB2, Wetzlar, Germany). The surface morphology of microcapsules was observed using a scanning electron microscope (SEM) (FEI XL-30 ESEM, Amsterdam, Netherlands) operated with $7 \mathrm{kV}$ acceleration voltage. Before performing the SEM observation, the samples were sputter-coated with gold using a vacuum sputter coater (Bal-tec SCD 005, Los Angeles, CA, USA) operated at $30 \mathrm{~mA}$ for $90 \mathrm{~s}$, to prevent the accumulation of static electric charge on the sample during electron irradiation. The thermal stability of microcapsules was evaluated using a thermogravimetric analyzer (TA Instruments TGA Q500, New Castle, DE, USA) under a nitrogen atmosphere at a heating rate of $10{ }^{\circ} \mathrm{C} \mathrm{min}-1$ from 25 to $600{ }^{\circ} \mathrm{C}$. The samples were previously dried during $24 \mathrm{~h}$ at $40{ }^{\circ} \mathrm{C}$ to remove the moisture. The core content of microcapsules was determined by Soxhlet extraction at approximately $120{ }^{\circ} \mathrm{C}$ in an oil bath. Xylene was used as solvent to extract tung oil for $5 \mathrm{~h} \mathrm{[23]} \mathrm{and} \mathrm{the} \mathrm{collected} \mathrm{deposit} \mathrm{was} \mathrm{dried} \mathrm{at} 60{ }^{\circ} \mathrm{C}$ for $24 \mathrm{~h}$. Then the core content of microcapsules was calculated by:

$$
w_{\text {core }}=\frac{M_{\text {microcapsule }}-M_{\text {shell }}}{M_{\text {microcapsule }}} \times 100 \%,
$$

where $W_{\text {core }}$ is the core content of microcapsule (wt\%), $M_{\text {microcapsule }}$ is the weight of microcapsule (g), and $M_{\text {shell }}$ is the weight of microcapsule sell (g).

\section{Preparation and characterization of self-healing coatings} Microcapsules were incorporated into polyurethane varnish and acrylate varnish by mechanical stirring at $200 \mathrm{rpm}$ for $5 \mathrm{~min}$. The addition was done at 10-12 wt\% concentrations. Either a self-healing coating or a control coating was coated on one side of the glass slide and then kept aside for curing for 7 days. The control coating was prepared with polyurethane varnish or acrylate varnish. After curing, the self-healing and control coatings were cut along a straight line with a razor blade. The healing behavior was observed using an optical microscopy (Leica DMLB2, Wetzlar, Germany) after 0 and 4 days. The healed region was observed using a scanning electron microscope (FEI XL-30 ESEM, Amsterdam, Netherlands) operated with $7 \mathrm{kV}$ acceleration voltage.

\section{Preparation of preservative-treated bamboo}

The preservatives were prepared referring to a Chinese patent [39] (Table 1). After removing outer skin and inner skin, bamboo samples with a dimension of $70 \mathrm{~mm}$ (longitudinal) $\times 20 \mathrm{~mm}$ (tangential) $\times 5 \mathrm{~mm}$ (radial) were prepared. The prepared bamboo samples were impregnated as follows: (i) impregnate at a vacuum of $-0.85 \mathrm{MPa}$ for $5 \mathrm{~min}$; (ii) impregnate at atmospheric pressure for $5 \mathrm{~min}$; (iii) impregnate at a vacuum of $-0.85 \mathrm{MPa}$ for $10 \mathrm{~min}$, and (iv) impregnate at atmospheric pressure for $10 \mathrm{~min}$. The retention of each preservative was calculated by [40]:

$$
\text { Ret }=\frac{c \times m_{\mathrm{G}} \times 1000}{V},
$$

where Ret is the preservative retention $\left(\mathrm{kg} \mathrm{m}^{-3}\right), c$ is the concentration of preservative (wt\%), $m_{\mathrm{G}}$ is the mass 
Table 1 Concentration and retention of preservatives

\begin{tabular}{llll}
\hline Preservative & Concentration $(\mathbf{w t} \%)$ & Retention $\left.\mathbf{~} \mathbf{~ g ~ ~}^{\mathbf{- 3}}\right)$ & SD of retention $\left(\mathbf{k g ~} \mathbf{~}^{\mathbf{3}}\right)$ \\
\hline PPZ-TEB & 0.06 & 0.1292 & 0.0378 \\
PPZ-TEB/IPBC & $0.06 / 0.12$ & $0.1358 / 0.2716$ & $0.0314 / 0.0629$ \\
PPZ-TEB/MCI-Ml & $0.06 / 0.3$ & $0.1349 / 0.6746$ & $0.0315 / 0.1577$ \\
CK $^{\text {a }}$ & 0 & 0 & 0
\end{tabular}

a CK was water without any preservatives

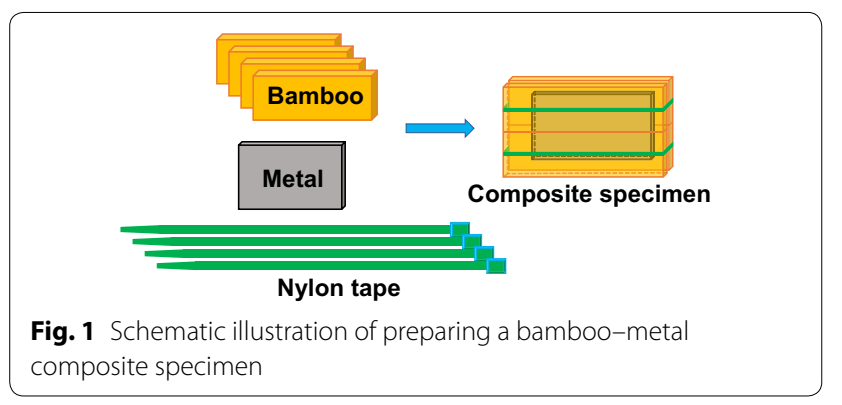

of preservative absorbed by bamboo $(\mathrm{g})$, and $V$ is the volume of bamboo $\left(\mathrm{cm}^{3}\right)$. The retentions are shown in Table 1. Finally, the treated bamboo samples were airdried in a well-ventilated place for 21 days prior to use.

\section{Accelerated corrosion tests}

A bamboo/metal composite specimen was assembled by placing a metal sample between four pieces of the preservative-treated bamboo, and fastening each with four nylon tapes (Fig. 1). The sizes of Q235 steel and $65 \mathrm{Mn}$ steel samples were $50 \mathrm{~mm}$ (length) $\times 30 \mathrm{~mm}$ (width) $\times 2 \mathrm{~mm}$ (thickness). The prepared composite specimens of each metal were randomly divided into five groups, four of which were coated with a self-healing coating or a control coating on the outer surface. In a previous test, we found that mechanical brushing seemed to be causing microcapsules to rupture, so manual brushing was adopted in this study. Finally, the coated composite specimens were air-dried in a well-ventilated place for 7 days prior to use.

Each of the above five groups of composite specimens was evenly divided into two groups. Referring to AWPA E12-08 [41] standard, the two groups were exposed to an atmosphere maintained at $49 \pm 3{ }^{\circ} \mathrm{C}$ and $90 \pm 3 \% \mathrm{RH}$ for $720 \mathrm{~h}$ and $2160 \mathrm{~h}$, respectively. For each kind of composite specimen, four samples were tested. After accelerated corrosion, the coatings were removed and the equilibrium moisture content of bamboo was measured.

Referring to AWPA E12-08 [41] and GB/T 165452015 [42] standards, the metal samples were cleaned and weighted (accurate to $0.001 \mathrm{~g}$ ). The procedure was as follows: before corrosion-(i) rinse metal samples with ethanol-acetone mixture $(1: 1 \mathrm{v} / \mathrm{v})$ to remove oil and grease and wipe dry; (ii) dry metal samples in a forced-draft or convection oven set at $40{ }^{\circ} \mathrm{C}$ for $12 \mathrm{~h}$, and (iii) place metal samples in a desiccator and then weigh after cooling to room temperature; and after corrosion-(i) brush lightly metal samples with a nylon brush to remove loose corrosion products; (ii) rinse metal samples with distilled water-37\% $\mathrm{HCl}$ mixture $(1: 1 \mathrm{v} / \mathrm{v})$ containing $3.5 \mathrm{~g}$ of hexamethylenetetramine $\left(\mathrm{C}_{6} \mathrm{H}_{12} \mathrm{~N}_{4}\right)$ under microsonic for $10 \mathrm{~min}$; (iii) dry metal samples in a forced-draft or convection oven set at $40{ }^{\circ} \mathrm{C}$ for $12 \mathrm{~h}$, and (iv) place metal samples in a desiccator and then weigh after cooling to room temperature.

\section{Mechanical property tests}

The probable negative effect of microcapsule embedment on the mechanical properties of self-healing coatings was investigated by impact damage test and adhesion strength test. According to the method reported by Chen et al. [25], impact damage test was carried out. The samples were impacted with an energy of $2.9219 \mathrm{~J}$, using an impact tester (Instron Dynatup $9250 \mathrm{HV}$, Norwood, MA, USA). It should be noted that when the energy was greater than this value, the bamboo samples cracked. For each kind of coating, eight samples were tested and then the photographs of the damaged regions were analyzed to measure the areas. Referring to ASTM D3359-17 [43] standard, tape test was conducted for investigation of the effect of microcapsule embedment on the adhesion strength. An X-cut was made through coatings to bamboo, pressure-sensitive tape was applied over the cut and then removed, and the adhesion strength was assessed qualitatively on the $0 \mathrm{~A}$ to $5 \mathrm{~A}$ scale $(5 \mathrm{~A}$, no peeling or removal; $4 \mathrm{~A}$, trace peeling or removal along incisions or at their intersection; $3 \mathrm{~A}$, jagged removal along incisions up to $1.6 \mathrm{~mm}$ on either side; $2 \mathrm{~A}$, jagged removal along most of incisions up to $3.2 \mathrm{~mm}$ on either side; $1 \mathrm{~A}$, removal from most of the area of the $\mathrm{X}$ under the tape; and $0 \mathrm{~A}$, removal beyond the area of the $\mathrm{X}$ ). For each kind of coating, eight samples were tested. 


\section{Results and discussion}

\section{Morphology and analysis of microcapsule}

To ensure uniformity throughout test [44, 45], five batches of microcapsules were combined in this study. The microcapsules recovered from the suspension were slightly yellow substances which could be observed with the naked eye (Fig. 2a). When the microcapsules ruptured, a yellow liquid consistent with the color of tung oil was released. Optical micrographs showed that microcapsules were spherical particles (Fig. 2b) and their diameter varied between 22 and $185 \mu \mathrm{m}$ (Fig. 2c). The mean, median and standard deviation of microcapsule diameter were $97 \mu \mathrm{m}, 95 \mu \mathrm{m}$ and $29 \mu \mathrm{m}$, respectively. SEM micrographs confirmed the non-porous and smooth surface morphology of microcapsules (Fig. 2d). Compared with the vascular systems, the morphology of microcapsules guarantees the storage role and the easy dispersion into the matrix [21, 23, 46, 47]. The core content plays an important role in the self-healing functionality of coating. The mean content of tung oil in microcapsules was found to be about $77 \mathrm{wt} \%$. This high core loading allows for more effective healing of microcracks in coating.
The thermal stability of microcapsules plays a great role in their storage and practical applications. The thermogravimetric (TG) curves of microcapsules and PUF are shown in Fig. 3. The TG curve of PUF consisted of two stages of weight loss with a rise in temperature, i.e., $25-220{ }^{\circ} \mathrm{C}$ and $220-600{ }^{\circ} \mathrm{C}$. The first stage attributed to the elimination of free

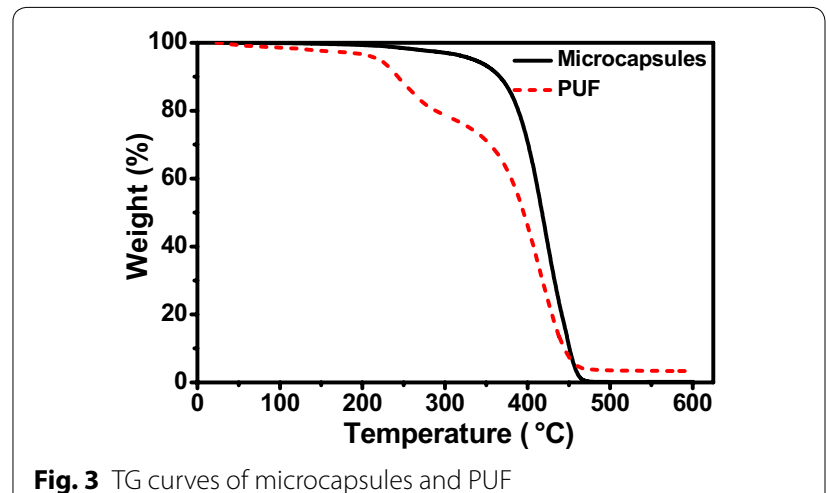

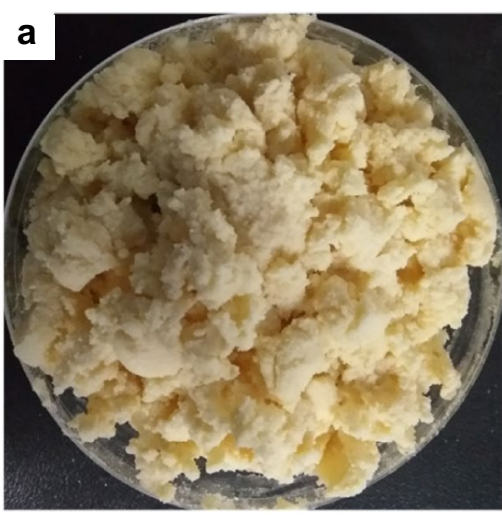
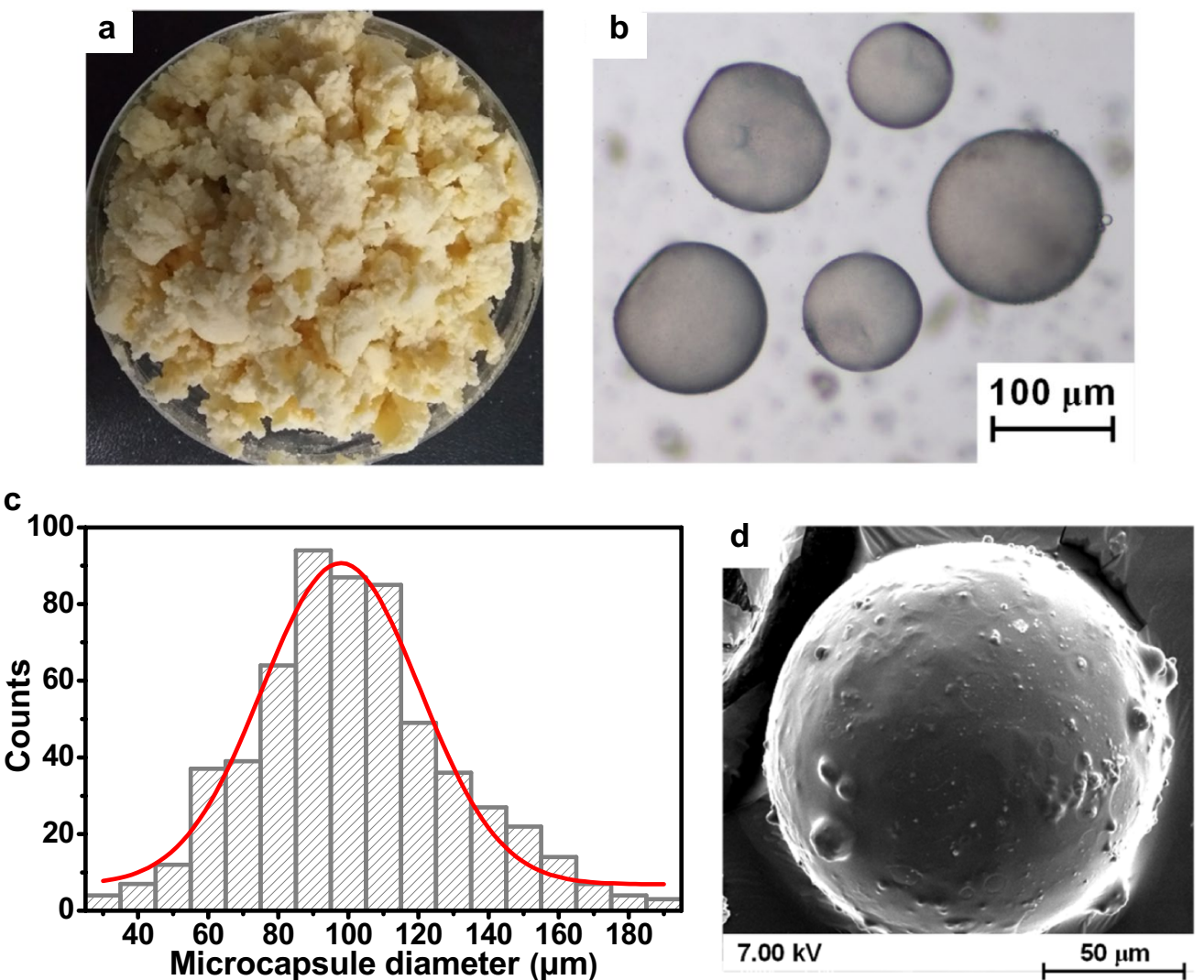

Fig. 2 a Microcapsules recovered from the suspension; $\mathbf{b}$ optical micrographs of microcapsules; c diameter distribution of microcapsules; d SEM micrographs of microcapsules 
formaldehyde, the decomposition of small molecule minor product and the evaporation of moisture. The second stage was mainly due to the decomposition of PUF. Tung oil is a material with excellent thermal stability and does not degrade at temperature below $350{ }^{\circ} \mathrm{C}$ [26]. Therefore, the thermal stability of microcapsules was limited by the PUF. With an increase in temperature to $350{ }^{\circ} \mathrm{C}$ nearby, a large scale of decreasing in mass was observed for the combined decomposing of tung oil and PUF. Accordingly, it is confirmed that the microcapsules contain both materials, i.e., tung oil (as core) and PUF (as shell). And the microcapsules can be stored and used under $220^{\circ} \mathrm{C}$.

\section{Self-healing behavior of coating}

As shown in Fig. 4a, b, a light-colored band was observed along the cut on the self-healing coatings after 4 days. SEM micrographs of healed region are shown in Fig. 4c, d. SEM micrographs confirmed that tung oil filled the damaged region. The results indicated that the self-healing coatings had the ability of self-healing damage. The self-healing mechanism of the coatings is the curing effect of tung oil released by the microcapsules. When microcracks propagate through the coating, tung oil is released from ruptured microcapsules by capillary action and automatically oxidized to repair the damaged region. Chemically, the healing mechanism could be that the $\mathrm{C}-\mathrm{H}$ bond adjacent to one of the double bonds within fatty acid of the tung oil automatically oxidizes to form an oxidized cross-linked film [48]. Moreover, it should be noted that the band only partially healed the microcracks, suggesting that the effectiveness of self-healing coatings may be limited to the size, orientation, and location of the damage site.

\section{Corrosion of ferrous metals exposed to preservative-treated bamboo}

Because local corrosion was observed on the surface of ferrous metals exposed to treated bamboo, the corrosion rate calculated by using Eq. (3) is inaccurate [41]:

$$
R=\frac{C \times W}{A \times T \times D},
$$

where $R$ is the corrosion rate (mil year $\left.{ }^{-1}\right), C$ is the units conversion constant, $3.44 \times 10^{6}\left(\mathrm{~h}\right.$ mil year $\left.{ }^{-1} \mathrm{~cm}^{-1}\right), W$ is the weight loss due to corrosion (g), $A$ is the area of metal surface exposed $\left(\mathrm{cm}^{2}\right), T$ is the time of exposure (h) and $D$ is the density of metal $\left(\mathrm{g} \mathrm{cm}^{-3}\right)$. Hence, the severity of corrosion was analyzed by weight loss in this study.

As shown in Fig. 5, the weight loss values of Q235 steel and $65 \mathrm{Mn}$ steel samples in the bamboo-metal composite specimens with the self-healing coatings were significantly lower than those with the control coatings after accelerated corrosion tests. After applying the selfhealing polyurethane and acrylate coatings, the average weight loss values of Q235 steel were reduced by $76.4 \%$ and $73.1 \%$ at $720 \mathrm{~h}$ and $44.2 \%$ and $43.0 \%$ at $2160 \mathrm{~h}$, respectively, and those of $65 \mathrm{Mn}$ steel were reduced by $74.3 \%$ and $69.8 \%$ at $720 \mathrm{~h}$ and $55.0 \%$ and $54.0 \%$ at $2160 \mathrm{~h}$, respectively. Moreover, the control coatings almost failed at $720 \mathrm{~h}$. This indicated that the self-healing coatings had a more positive effect on inhibiting corrosion than control coatings.

Unlike steel and concrete, the ferrous metal corrosion of treated bamboo is affected by preservatives and bamboo chemical compositions. Generally, the preservatives and chemicals are corrosive only after forming an electrolytic solution. Thus, the ferrous metal corrosion of treated bamboo is directly affected by the moisture content of bamboo. As shown in Fig. 6, the equilibrium moisture contents of treated bamboo with the self-healing coatings were lower than those with the control coatings
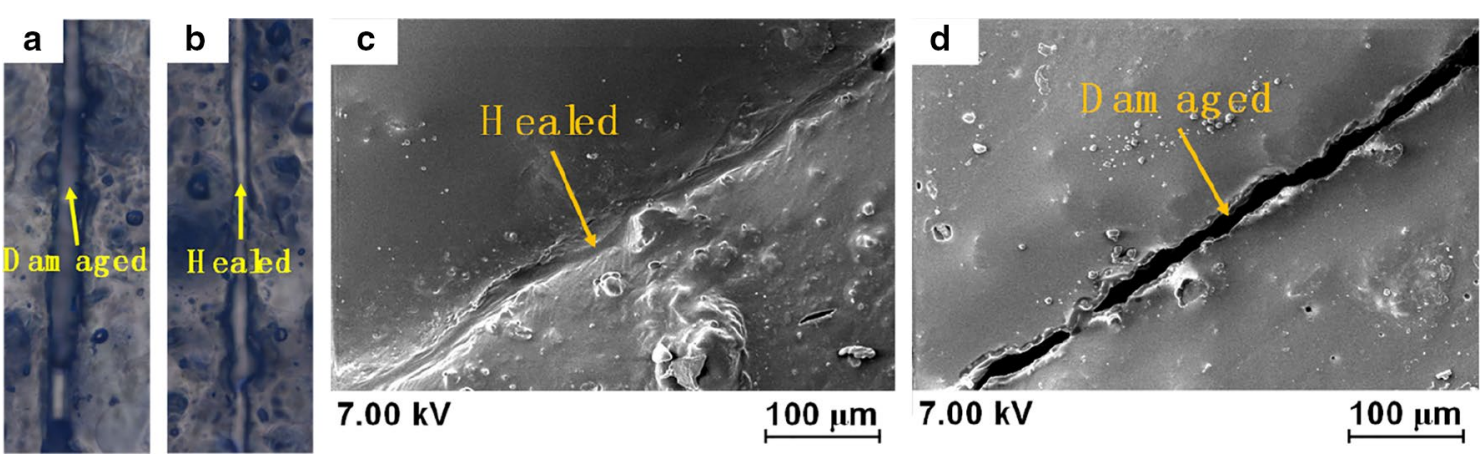

Fig. 4 Optical micrographs of the healed region on self-healing coatings after $\mathbf{a} 0$ and $\mathbf{b} 4$ days; SEM micrographs of the healed region on self-healing coating; $\mathbf{c}$ self-healing coatings; $\mathbf{d}$ control coatings 


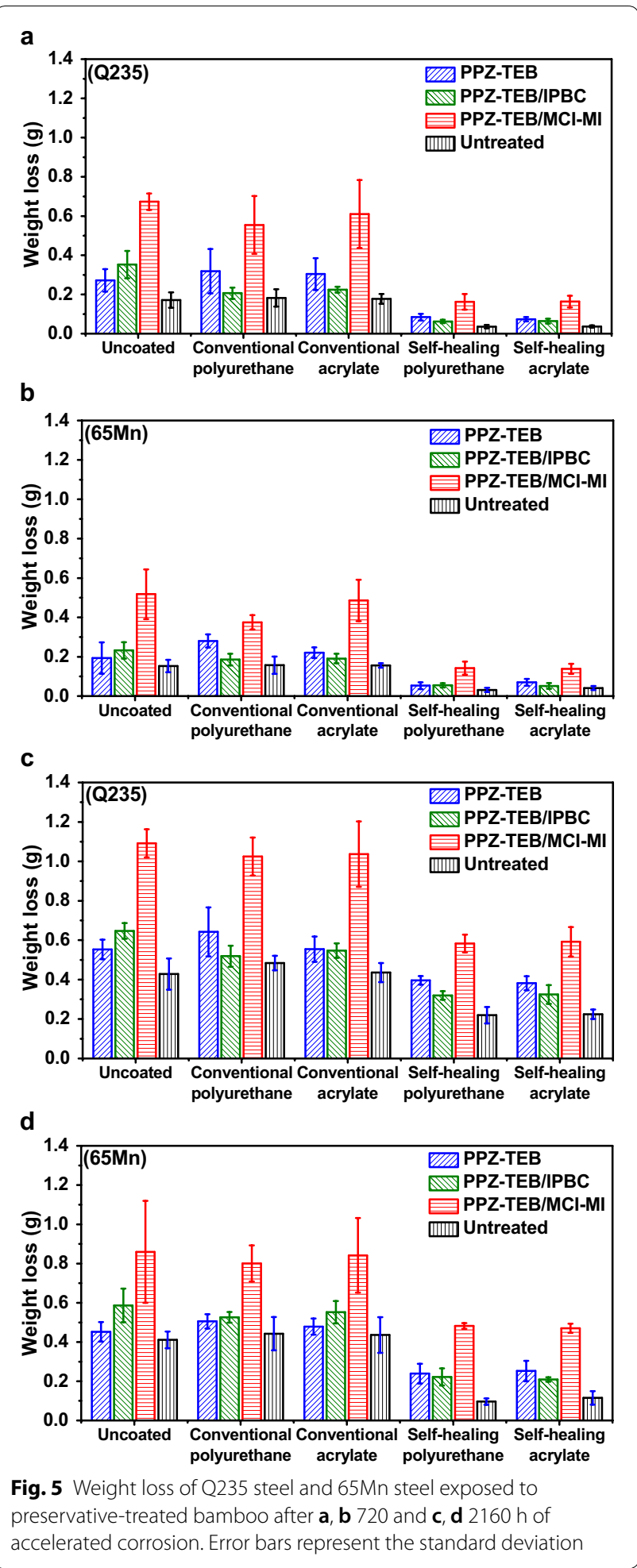

at $720 \mathrm{~h}$. This indicated that the self-healing coatings can better control the moisture content of bamboo, thereby inhibiting the occurrence of corrosion. Additionally, it should be noted that the equilibrium moisture contents of treated bamboo with the self-healing coatings was close to those with the control coatings at $2160 \mathrm{~h}$. This suggested that self-healing coatings also gradually failed over time. However, the self-healing coatings failed much slower than the control coatings.

The coating thickness was considered as a potential variable affecting waterproof performance. To avoid the influence of the thickness on the test, the coating thickness was adjusted by the number of brushing. The selfhealing coatings were applied twice and the control coatings were applied three times. This brushing process was done by one person. As shown in Fig. 7, the mean thickness of the four types of coatings was $347 \mu \mathrm{m}$, $375 \mu \mathrm{m}, 356 \mu \mathrm{m}$, and $363 \mu \mathrm{m}$, respectively. And there was no significant difference in coating thickness $(p>0.05)$. In addition, in a previous test, we found that the coating failure time of manual brushing seemed earlier than that of mechanical brushing, although the coating thickness of manual brushing was thicker than that of mechanical brushing. This may be due to the result that manual brushing is relatively more prone to defects. Therefore, further study will focus on the influence of brushing method on coating performance.

Zelinka and Lebow [49] investigated the corrosiveness of Cu-TEB-, Cu-PPZ-TEB- and PPZ-TEB-imidaclopridtreated wood towards galvanized wires and concluded that the difference between PPZ-TEB-imidacloprid and the untreated control was not statistically significant while $\mathrm{Cu}$-TEB and $\mathrm{Cu}$-PPZ-TEB were significantly higher than PPZ-TEB-imidacloprid and the untreated control. Also, IPBC and MCI-MI themselves may be not corrosive, since they are often used as metalworking fluids. Moreover, in our previous study on the corrosion rates of Q235 steel in PPZ-TEB solution and its emulsifier [50], it was found that the corrosion rates were positively correlated with the emulsifier content. Thus, in this study, the emulsifier may be the corrosion source of the organic preservatives. Use of low-corrosive emulsifiers will be the second research objective in further work.

\section{Mechanical property of coating}

It was suspected that microcapsule embedment may interfere with the mechanical bonding between bamboo and coating and the curing and three-dimensional crosslinking of coating, consequently reducing the mechanical property of coating. Thus, impact damage test and adhesion strength test were performed. As shown in Fig. 8, the damaged areas of the self-healing coatings were close to those of the control coatings. Furthermore, all coatings exhibited impact dents exclusively, and no debonding and delamination were observed. This indicated no significant loss in the impact resistance offered by the self-healing and control coatings. And the 

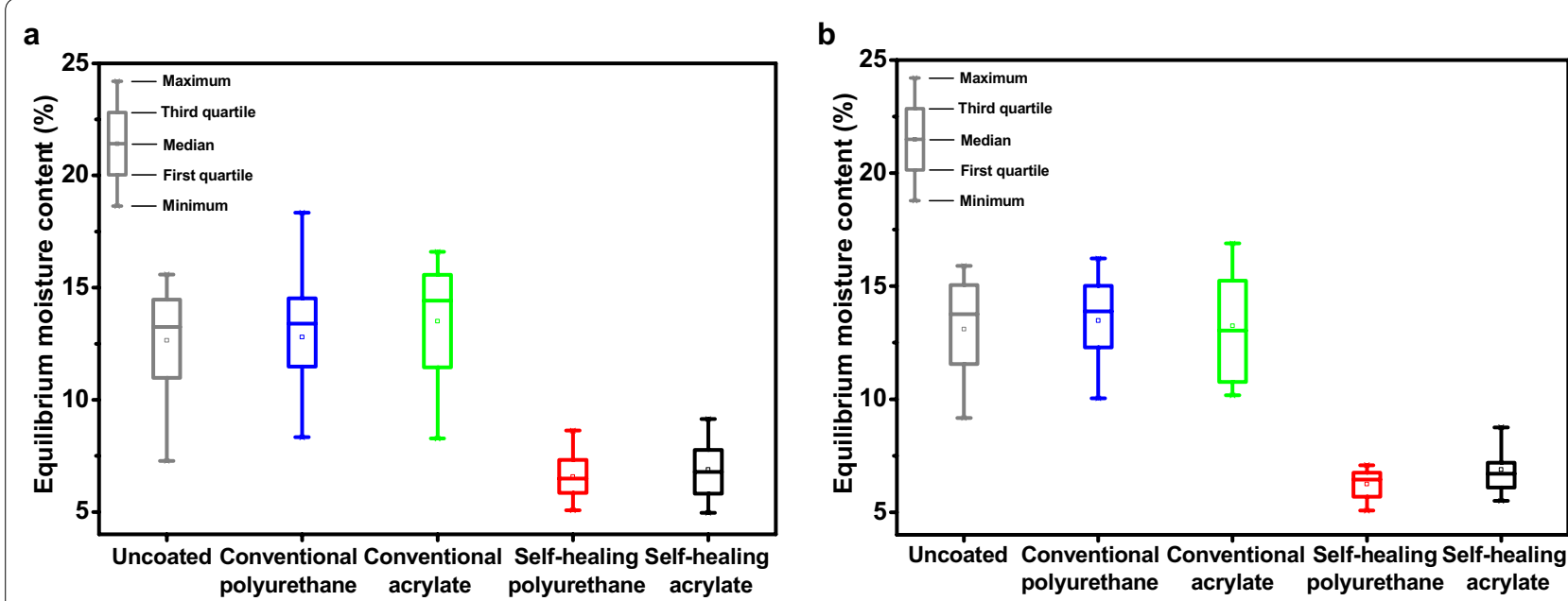

d

d
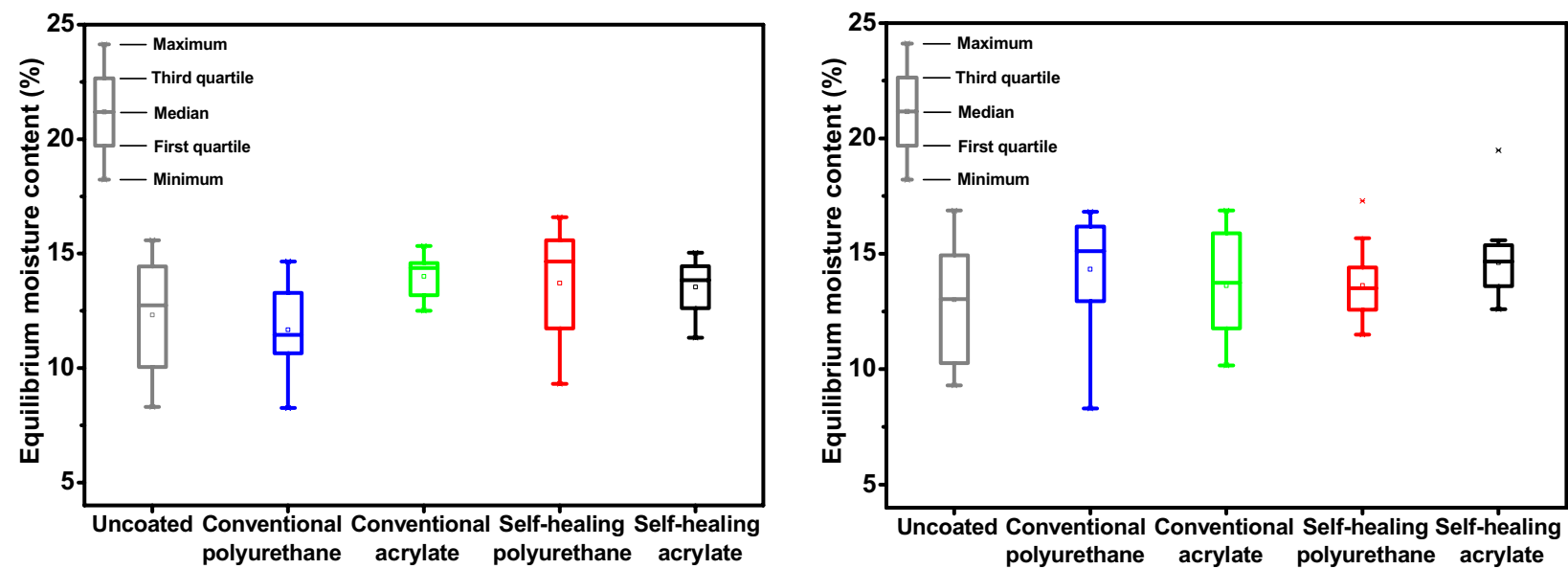

Fig. 6 Equilibrium moisture content of preservative-treated bamboo after $\mathbf{a}, \mathbf{b} 720$ and $\mathbf{c}, \mathbf{d} 2160 \mathrm{~h}$ of accelerated corrosion

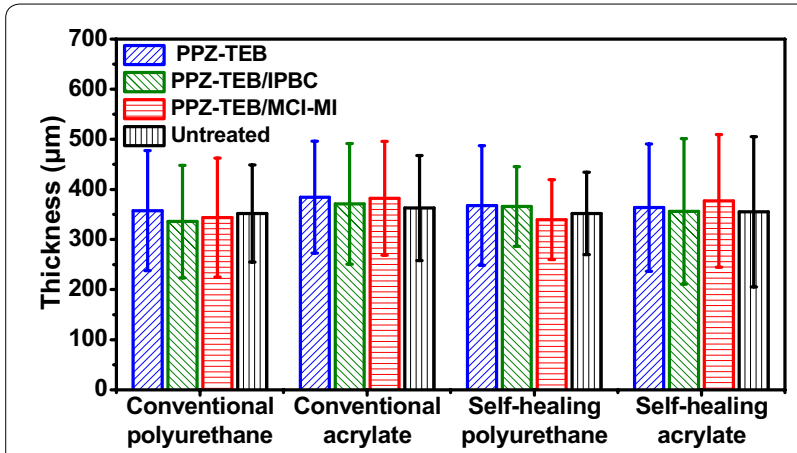

Fig. 7 Thickness of coatings. Error bars represent the standard deviation

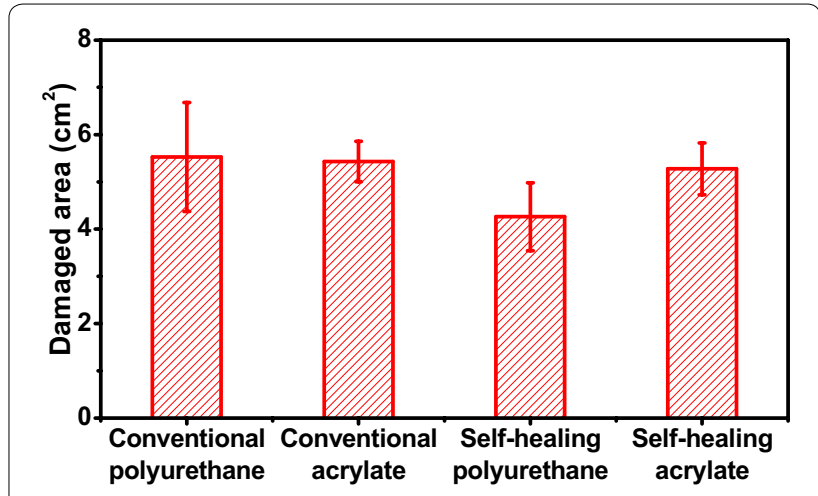

Fig. 8 Damaged area of coatings. Error bars represent the standard deviation 
mean adhesion strength of all the coatings can reach $5 \mathrm{~A}$, i.e., no peeling or removal, indicating that the incorporation of microcapsules did not almost reduce the ability of the coating adhesion.

\section{Conclusion}

This study investigated the effect of self-healing coatings on the corrosion of ferrous metals exposed to preservative-treated bamboo. The characterization of microcapsules revealed that microcapsules were spherical, non-porous and smooth-faced particles with good thermal stability and high core loading. Optical and SEM micrographs confirmed that upon coatings damage, tung oil released from the ruptured microcapsules filled and cured the damaged region. In accelerated corrosion tests, the weight loss values of Q235 steel and 65Mn steel samples in the bamboo-metal composite specimens with the self-healing coatings were significantly lower than those with the control coatings. Compared with the control coatings, the self-healing coatings can better control the moisture content of bamboo. However, the self-healing coatings also gradually failed over time. In mechanical property tests, microcapsule embedment has no negative effect on the mechanical properties of self-healing coatings. These results indicated that self-healing coating is a feasible method of inhibiting effectively the corrosion of ferrous metals exposed to preservative-treated bamboo.

\section{Abbreviations}

PUF: Poly(urea-formaldehyde); CCA: Chromated copper arsenate; ACQ: Alkaline copper quat; CuAz: Copper azole; IPBC: lodopropynyl butylcarbamate; PPZ: Propiconazole; TEB: Tebuconazole; MCl-MI: Isothiazolinone; $\mathrm{NH}_{4} \mathrm{Cl}$ : Ammonium chloride; PVA: Poly(vinyl alcohol); SDS: Sodium dodecyl sulfate; SEM: Scanning electron microscope; TG: Thermogravimetric.

\section{Acknowledgements}

This work was financial supported by the National Key R\&D Program of China (Grant No. 2017YFD0600803).

\section{Authors' contributions}

QW designed and performed the experiments, and was a major contributor in writing the manuscript. QW, JC, XL, SY and MJ reviewed and edited the manuscript, and decided the final version of the manuscript. All authors contributed to interpretation and discussed results. All authors read and approved the final manuscript.

\section{Funding}

This work was financial supported by the National Key R\&D Program of China (Grant No. 2017YFD0600803).

\section{Availability of data and materials}

The datasets used and/or analyzed during the current study are available from the corresponding author on reasonable request.

\section{Competing interests}

The authors declare that they have no competing interests.

\section{Author details}

${ }^{1}$ Research Institute of Wood Industry, Chinese Academy of Forestry, Beijing 100091, People's Republic of China. ${ }^{2}$ College of Materials Science and Technology, Beijing Forestry University, Beijing 100083, People's Republic of China. ${ }^{3}$ Bamboo and Rattan Science and Technology Laboratory, International Centre for Bamboo and Rattan, Beijing 100102, People's Republic of China.

Received: 9 November 2019 Accepted: 27 February 2020

Published online: 09 March 2020

\section{References}

1. Dixon PG, Gibson $L$ (2014) The structure and mechanics of Moso bamboo material. J R Soc Interface 11:20140321. https://doi.org/10.1098/ rsif.2014.0321

2. Wei X, Zhou H, Chen F, Wang G (2019) Bending flexibility of Moso bamboo (Phyllostachys Edulis) with functionally graded structure. Materials 12:2007. https://doi.org/10.3390/ma12122007

3. Sharma B, Gatóo A, Bock M, Ramage M (2015) Engineered bamboo for structural applications. Constr Build Mater 81:66-73. https://doi. org/10.1016/j.conbuildmat.2015.01.077

4. Sharma B, Gatóo A, Ramage MH (2015) Effect of processing methods on the mechanical properties of engineered bamboo. Constr Build Mater 83:95-101. https://doi.org/10.1016/j.conbuildmat.2015.02.048

5. Sassu M, De Falco A, Giresini L, Puppio ML (2016) Structural solutions for low-cost bamboo frames: experimental tests and constructive assessments. Materials 9:346. https://doi.org/10.3390/ma9050346

6. Okahisa Y, Yoshimura T, Imamura Y (2006) Seasonal and height-dependent fluctuation of starch and free glucose contents in Moso bamboo (Phyllostachys pubescens) and its relation to attack by termites and decay fungi. J Wood Sci 52:445-451. https://doi.org/10.1007/s10086-005-0776-x

7. Liese W, Tang TKH (2015) Chapter 9 preservation and drying of bamboo. In: Liese W, Köhl M (eds) Bamboo: the plant and its uses. Springer, Cham, pp 257-297

8. Möller R, Mild G (2019) Protection of Moso bamboo (Phyllostachys pubescens) materials against fungal decay and discolouration by treatment with wood preservatives. Eur J Wood Prod 77:139-145. https://doi. org/10.1007/s00107-018-1371-3

9. Kear G, Wú H, Jones MS (2009) Weight loss studies of fastener materials corrosion in contact with timbers treated with copper azole and alkaline copper quaternary compounds. Corros Sci 51:252-262. https://doi. org/10.1016/j.corsci.2008.11.012

10. Zelinka SL, Sichel RJ, Stone DS (2010) Exposure testing of fasteners in preservative treated wood: gravimetric corrosion rates and corrosion product analyses. Corros Sci 52:3943-3948. https://doi.org/10.1016/j. corsci.2010.08.014

11. Scurlock JMO, Dayton DC, Hames B (2000) Bamboo: an overlooked biomass resource? Biomass Bioenerg 19:229-244. https://doi.org/10.1016/ s0961-9534(00)00038-6

12. Hong M, Wei W, Yang Z, Yuan S, Yang X, Gu X, Huang F, Zhang Z (2016) Effects of timber harvesting on Arundinaria spanostachya bamboo and feeding-site selection by giant pandas in Liziping Nature Reserve, China. Forest Ecol Manag 373:74-80. https://doi.org/10.1016/j.forec 0.2016 .04 .039

13. Jack EJ, Smedley SI (1987) Electrochemical study of the corrosion of metals in contact with preservative-treated wood. Corrosion 43(5):266-275. https://doi.org/10.5006/1.3583147

14. Zelinka SL, Rammer DR, Stone DS, Gilbertson JT (2007) Direct current testing to measure corrosiveness of wood preservatives. Corros Sci 49:1673-1685. https://doi.org/10.1016/j.corsci.2006.10.001

15. Baechler RH (1934) Corrosion of metal fastenings in zinc-chloride-treated wood. Ind Eng Chem 26(12):1336-1338. https://doi.org/10.1021/ie503 00a030

16. Dennis JK, Zou C, Short NR (1995) Corrosion behaviour of zinc and zinc alloy coated steel in preservative treated timber. Trans IMF 73(3):96-101. https://doi.org/10.1080/00202967.1995.11871067

17. Short NR, Dennis JK (1997) Corrosion resistance of zinc-alloy coated steel in construction industry environments. Trans IMF 75(2):47-52. https://doi. org/10.1080/00202967.1997.11871142

18. Krilov A, Lasander WH (1988) Acidity of heartwood and sapwood in some eucalypt species. Holzforschung 42(4):253-258. https://doi.org/10.1515/ hfsg.1988.42.4.253 
19. Bhushan B (2018) Chapter 23 self-healing materials and defense mechanisms. Biomimetics: bioinspired hierarchical-structured surfaces for green science and technology, 3rd edn. Springer, Cham, pp 911-958

20. Blaiszik BJ, Kramer SLB, Olugebefola SC, Moore JS, Sottos NR, White SR (2010) Self-healing polymers and composites. Annu Rev Mater Res 40:179-211. https://doi.org/10.1146/annurev-matsci-070909-104532

21. Zhu DY, Rong MZ, Zhang MQ (2015) Self-healing polymeric materials based on microencapsulated healing agents: from design to preparation. Prog Polym Sci 49-50:175-220. https://doi.org/10.1016/j.progpolyms ci.2015.07.002

22. An S, Lee MW, Yarin AL, Yoon SS (2018) A review on corrosion-protective extrinsic self-healing: comparison of microcapsule-based systems and those based on core-shell vascular networks. Chem Eng J 344:206-220. https://doi.org/10.1016/j.cej.2018.03.040

23. Samadzadeh M, Boura SH, Peikari M, Ashrafi A, Kasiriha M (2011) Tung oil: an autonomous repairing agent for self-healing epoxy coatings. Prog Org Coat 70:383-387. https://doi.org/10.1016/j.porgcoat.2010.08.017

24. Thanawala K, Khanna AS, Raman RKS (2015) Tung oil-urea formaldehyde microcapsules for anti-corrosive self-healing epoxy coatings. J Mater Sci Surf Eng 2(3):151-156

25. Chen Y, Xia C, Shepard Z, Smith N, Rice N, Peterson AM, Sakulich A (2017) Self-healing coatings for steel-reinforced concrete. ACS Sustain Chem Eng 5:3955-3962. https://doi.org/10.1021/acssuschemeng.6b03142

26. Li H, Cui Y, Li Z, Zhu Y, Wang H (2018) Fabrication of microcapsules containing dual-functional tung oil and properties suitable for self-healing and self-lubricating coatings. Prog Org Coat 115:164-171. https://doi. org/10.1016/j.porgcoat.2017.11.019

27. Schultz TP, Nicholas DD (2003) Chapter 26 a brief overview of nonarsenical wood preservative systems. In: Goodell B, Nicholas DD, Schultz TP (eds) Wood deterioration and preservation: advances in our changing world. American Chemical Society, Washington, DC, pp 420-432

28. Schultz TP, Nicholas DD, Preston AF (2007) A brief review of the past, present and future of wood preservation. Pest Manag Sci 63:784-788. https ://doi.org/10.1002/ps.1386

29. Cao J, Jiang $X(2014)$ Chapter 22 preservation of wood and other sustainable biomaterials in China. In: Schultz TP, Goodell B, Nicholas DD (eds) Deterioration and Protection of Sustainable Biomaterials. American Chemical Society, Washington, DC, pp 363-383

30. Freeman MH, Nicholas DD, Schultz TP (2006) Chapter 2 nonarsenical wood protection: alternatives for chromated copper arsenate, creosote and pentachlorophenol. In: Townsend TG, Solo-Gabriele H (eds) Environmental impacts of treated wood. CRC Press, Boca Raton, pp 19-36

31. Kumar A, Stephenson LD, Murray JN (2006) Self-healing coatings for steel. Prog Org Coat 55:244-253. https://doi.org/10.1016/j.porgc oat.2005.11.010

32. Thanawala K, Mutneja N, Khanna AS, Raman RKS (2014) Development of self-healing coatings based on linseed oil as autonomous repairing agent for corrosion resistance. Materials 7:7324-7338. https://doi.org/10.3390/ ma7117324

33. Kim D, Yu H, Yang H, Cho Y, Lee K, Chung C (2017) Microcapsule-type selfhealing protective coating for cementitious composites with secondary crack preventing ability. Materials 10:114. https://doi.org/10.3390/ma100 20114

34. Kim D, Cho Y, Choi J, Kim B, Jin S, Chung C (2017) Low-temperature self-healing of a microcapsule-type protective coating. Materials 10:1079. https://doi.org/10.3390/ma10091079
35. Archila H, Kaminski S, Trujillo D, Escamilla EZ, Harries KA (2018) Bamboo reinforced concrete: a critical review. Mater Struct 51:102. https://doi. org/10.1617/s11527-018-1228-6

36. GB/T 700-2006 (2006) Carbon structural steels. China National Standard, Beijing (in Chinese)

37. GB/T 1222-2007 (2007) Spring steels. China National Standard, Beijing (in Chinese)

38. Hansen MK, Larsen M, Cohr K (1987) Waterborne paints: a review of their chemistry and toxicology and the results of determinations made during their use. Scand J Work Environ Health 13:473-485. https://doi. org/10.2307/40965507

39. Jiang M, Ma X, Li X, Xi L (2017) Combination of triazole formulations for decay and stain control and its preparation method. CHN Patent ZL 201610631765.4, 26 Dec 2017. (in Chinese)

40. GB/T 29905-2013 (2013) Laboratory method of determining the leachability of wood preservatives. China National Standard, Beijing (in Chinese)

41. AWPA E12-08 (2012) Standard method of determining corrosion of metal in contact with treated wood. American Wood Protection Association, Birmingham

42. GB/T 16545-2015 (2015) Corrosion of metals and alloys-removal of corrosion products from corrosion test specimens. China National Standard, Beijing (in Chinese)

43. ASTM D3359-17 (2017) Standard test methods for rating adhesion by tape test. ASTM international, West Conshohocken

44. Wang R, Li H, Hu H, He X, Liu W (2009) Preparation and characterization of self-healing microcapsules with poly(urea-formaldehyde) grafted epoxy functional group shell. J Appl Polym Sci 113:1501-1506. https://doi. org/10.1002/app.30001

45. Safaei F, Khorasani SN, Rahnama H, Neisiany RE, Koochaki MS (2018) Single microcapsules containing epoxy healing agent used for development in the fabrication of cost efficient self-healing epoxy coating. Prog Org Coat 114:40-46. https://doi.org/10.1016/j.porgcoat.2017.09.019

46. Boura SH, Peikari M, Ashrafi A, Samadzadeh M (2012) Self-healing ability and adhesion strength of capsule embedded coatings - micro and nano sized capsules containing linseed oil. Prog Org Coat 75:292-300. https:// doi.org/10.1016/j.porgcoat.2012.08.006

47. Fadila M, Chauhan DS, Quraishi MA (2018) Smart coating based on ureaformaldehyde microcapsules loaded with benzotriazole for corrosion protection of mild steel in 3.5\% NaCl. Russ J Appl Chem 91(10):17211728. https://doi.org/10.1134/s107042721810021x

48. Tatiya PD, Mahulikar PP, Gite VV (2016) Designing of polyamidoaminebased polyurea microcapsules containing tung oil for anticorrosive coating applications. J Coat Technol Res 13(4):715-726. https://doi. org/10.1007/s11998-015-9780-2

49. Zelinka SL, Lebow S (2015) Corrosion of wires on wooden wire-bound packaging crates. In: NACE international corrosion 2015 conference \& expo, Dallas, TX, USA, 15-19 March 2015, Paper No. 5617

50. Xi LX (2014) Study on preparation and properties of triazole wood preservatives. Ph.D. thesis, Chinese Academy of Forestry, Beijing (in Chinese with summary in English)

\section{Publisher's Note}

Springer Nature remains neutral with regard to jurisdictional claims in published maps and institutional affiliations. 